\title{
Cariprazine in Three Acute Patients with Schizophrenia: A Real-World Experience
}

This article was published in the following Dove Press journal:

Neuropsychiatric Disease and Treatment

\author{
Jose M Montes' \\ Paloma Montes ${ }^{2}$ \\ Daniel Hernández- \\ Huerta $\mathbb{I D}^{3}$ \\ 'Psychiatry Service, CIBERSAM, IRYCIS, \\ Hospital Universitario Ramóny Cajal, \\ Madrid, Spain; ${ }^{2}$ Psychiatry Service, \\ Hospital Universitario de Móstoles \\ Madrid, Spain; ${ }^{3}$ Psychiatry Service, \\ Hospital Universitario Ramón y Cajal, \\ Madrid, Spain
}

\begin{abstract}
There are still some unmet needs in the treatment of schizophrenia like the persistence of negative symptoms. Cariprazine is a new-generation antipsychotic with partial agonism of the dopamine receptors, distinct from other antipsychotics by its 10 times greater affinity for D3 receptors. This mechanism of action could be especially favorable on patients with predominant negative symptoms. This report is showing three clinical cases of acute schizophrenia exacerbation that required hospitalization and were successfully treated with cariprazine. All of them had predominant positive symptoms and two of them had substance use. Efficacy of cariprazine was also crucial on negative and cognitive symptoms with excellent tolerability.
\end{abstract}

Keywords: schizophrenia, cariprazine, antipsychotics, negative symptoms, case report

\section{Introduction}

Schizophrenia is a complex and chronic mental disorder that affects between $0.4 \%$ and $1.5 \%$ of the world population. ${ }^{1}$ It is also one of the most disabling psychiatric conditions and implies elevated rates of treatment, personal and social costs. ${ }^{2,3}$ Schizophrenia involves positive, negative, emotional and cognitive symptoms, ${ }^{4}$ but clinical presentations vary, with specific symptoms being more prominent in some patients than in others. ${ }^{5}$

Currently, antipsychotics are considered the mainstay of treatment and tend to be very effective in controlling positive symptoms, although they have a lower impact on the rest of the symptoms. ${ }^{6}$ Antipsychotics are crucial in the treatment of acute episodes but also in decreasing relapsing rates. ${ }^{7}$ Poor adherence to treatment is probably one of the most relevant modifiable causes of relapse and hospitalization after first episodes of schizophrenia, ranging from $20 \%$ to $89 \%{ }^{8}$ Non-adherence is a complex phenomenon that could be caused by many reasons, including poor insight, inadequate therapeutic alliance and lack of efficacy or poor tolerability of medication.

Antipsychotics have evolved from classic to newer generation agents with at least similar efficacy in positive symptoms but reducing some common side effects like extrapyramidal symptoms or tardive dyskinesia and globally improving tolerability. ${ }^{9,10}$ Nevertheless, many second-generation antipsychotic drugs are likely to induce metabolic side effects such as weight gain, higher plasma glucose levels, and other altered metabolic parameters, ${ }^{11}$ with an increased risk of cardiovascular mortality. ${ }^{12}$ Furthermore, there are still some unmet needs in the treatment of schizophrenia like the persistence of negative symptoms which has been associated with poor functional outcomes. ${ }^{13}$
Psychiatry Service, Hospital Universitario Ramón y Cajal, Carretera Colmenar Km 9, I, Madrid, 28034, Spain

Tel +34 9l 3369152

Fax +34913368483

Email j_m_montes@hotmail.com

Neuropsychiatric Disease and Treatment 2021:17 291-296 
Cariprazine is a new-generation antipsychotic, approved by the US Food and Drug Administration (FDA) for the treatment of schizophrenia and manic or mixed episodes in adults ${ }^{14,15}$ and by the European Medicines Agency (EMA) for the management of schizophrenia. ${ }^{16}$ Cariprazine is a partial agonist of the dopamine receptors being distinct from other antipsychotics by its 10 times greater affinity for D3 dopamine receptors, known for being an important key in cognition and affective modulation. ${ }^{17}$ Clinical evidence has shown that cariprazine could be especially favorable on patients with predominant negative symptoms with an excellent tolerability profile. ${ }^{16}$ In this regard, a recent clinical review has highlighted that, across all studies, common side effects of cariprazine treatment are represented by akathisia, extrapyramidal symptoms, insomnia, headache, dizziness, tremor, and gastrointestinal disturbances. ${ }^{18}$

Clinical trials are mandatory to show efficacy, but they are not representative of what happens when used in daily clinical practice with more complex patients than those included in clinical trials. Thus, real-world clinical cases could help to improve the knowledge of actual effectiveness and tolerability of cariprazine. This report is showing three clinical cases of acute schizophrenia exacerbation that required hospitalization and were successfully treated with cariprazine. All of them had predominant positive and negative symptoms and two of them had substance use comorbidity.

\section{Description of the Case Reports Case I}

A 31-year-old Russian man, living in Spain for the last 8 years voluntarily came to the emergency room of Hospital Ramon y Cajal sent by his family doctor who observed possible psychotic symptoms.

During the psychiatric interview, his autopsychic and allopsychic orientations were preserved. He was cooperative but anxious, verbalizing self-referential and persecutory delusion with a low systematization speech. He also described hearing voices in the last 2 weeks. He reported that in the waiting room he had the perception that staff and patients were watching him and communicating with each other about his movements and position. He also believed that they could have control of their cell phones and other devices (ie, messages through television), as well as surveillance through cameras and microphones at home. He also perceived strange odors in the air and recognized beliefs of being poisoned through drugs or even the cigarettes he smokes, reason why he has stopped smoking.

On an emotional level, he was on a subdepressive mood of almost a year of evolution with a social isolation tendency. No previous hyperthymic episodes were detected. He was suffering insomnia due to the hearing of voices inside his head, but his appetite was preserved. No suicide thoughts were referred at the moment of the exploration but had been present in the past.

The patient acknowledged practicing chemsex often during the last 2 years, being the last time 1 week before the hospital admission. During that last practice, he had a polydrug use of methamphetamine, alcohol, cocaine and other substances. The patient associated the onset of the psychotic symptoms with the substance use, but his partner commented they were present at lower intensity during abstinent periods as well in the last year.

Several complementary tests were performed, such as blood tests (general biochemistry, hemogram, coagulation, vitamin B12, folic acid, TSH), cranial CT and lumbar puncture, as well as evaluation by the Infectious Diseases and Neurology services, excluding acute decompensation of his medical illness that could explain current symptoms.

The patient had a medical history of HIV diagnosed 8 years ago, treated with triple antiviral therapy (bictegravir, emtricitabine and tenofovir alafenamide), chronic hepatitis $\mathrm{C}$ and successfully treated syphilis.

Psychiatric history was absent, but the patient expressed depressive symptomology since adolescence. No family psychiatric history was known.

$\mathrm{He}$ started substances abuse (methamphetamine, mephedrone, cocaine, alcohol and other unknown substances) during chemsex with a frequency of 2-3 times per month during the last 2 years with some rare periods of abstinence of few months.

The patient was admitted to the Inpatient Unit. At the moment of admission, he was alert and with preserved orientation, without signs of intoxication, but showing some low psychomotor inhibition. He also showed parsimonious and hypophonic speech, somehow limited by the language barrier. Delusional ideas of persecution and selfreference were present, with possible phenomena of reading and thought broadcasting and moments of thought blocking. Auditory pseudo-hallucinations and perception of unpleasant odors related to being poisoned were observed and not denied by the patient, which caused anxiety in paroxysms. The patient had total insomnia. No 
self or hetero-aggressivity behavior was present but he referred passive death thoughts. The judgment of reality was altered.

Since his admission to the Psychiatry Unit, cariprazine $3 \mathrm{mg}$ was prescribed. The patient was gradually showing an improvement in anxiety and repercussion of the psychotic symptoms as could be seen by his gradual adaptation to the unit and without observing reactive behaviors to them. The medication was well tolerated and at day 7 the psychotic symptomatology was almost remitted making adequate criticism. His mood improved with the understanding of the pathological mechanism underlying delusions and hallucinations. The patient was discharged from the Unit with the recommendations to continue pharmacological treatment and follow-up at the outpatient clinic.

\section{Case 2}

A 54-year-old black woman came to the emergency department brought by an ambulance after being found unconscious in her bed. The patient ingested all the pills she had at home. After medical stabilization, she was admitted to the Inpatient Unit. The patient was born in Cuba and moved to Spain at the age of 25. Divorced and married again. She lived with her current husband and her daughter and was unemployed. No medical condition or substance abuse had experienced in the past. Regarding mental illness, she had paranoid psychotic symptoms focused in her job that required admission and was treated with olanzapine $15 \mathrm{mg}$ /day ten years ago. During these last years, the patient had undergone follow-up at the Mental Health Center. She continued on olanzapine but the dose of olanzapine was gradually reduced to $5 \mathrm{mg}$ per day and duloxetine $60 \mathrm{mg}$ was added because she referred depressive symptoms. Despite all of this, in the last year, her functionality had been poor and she had tendency to apathy, low activity and social withdrawal, symptoms that could be characterized like negative symptoms without apparent positive symptoms. Nevertheless, last 8 weeks, her husband said she has been more absent, with moments in which she stated hearing critical comments from neighbors and felt they were entering her house to rob and move her things around to annoy her. She also had delusions of persecution when occasionally leaving the house, thinking people were watching her.

The patient refused to take olanzapine after admission because of weight gain and drowsiness, two common side effects associated with this medication. Cariprazine $3 \mathrm{mg}$ at night was prescribed and diazepam was added at $10 \mathrm{mg}$ to promote rest.

The first days of her admission, she was very hostile to the staff with moments of verbal aggressiveness and other periods when she was isolated in her room. She even refused to eat. On the third day, cariprazine was increased to $6 \mathrm{mg}$ since it was well tolerated and an improvement in her behavior was experienced on day 8 of admission. She started to talk to other patients and showed some criticism of the delusional thought about neighbors entering her home. Gradually, her mood improved, and she expressed desire to resume her daily life by returning home. Also, the thoughts of death disappeared. The patient accepted current treatment, saying that it has been useful for improving his mood and feeling better.

\section{Case 3}

A 36-year-old Caucasian woman was admitted to the Inpatient Unit after an episode of agitation in the supermarket during the quarantine starting in March 2020. She is single but living with her 14-year-old daughter. She experienced a psychotic episode some months ago and was treated with aripiprazole up to $15 \mathrm{mg}$ per day that was reduced to $10 \mathrm{mg} 3$ months ago due to drowsiness. The patient was not working since that episode. She had no medical history but smokes cannabis since adolescence.

Due to the quarantine, the patient referred increasing anxiety symptoms related to the risk of coronavirus contagion. She acknowledged to increase cannabis consumption to reduce the anxiety and fear associated to the pandemic. She started to verbalize that she had been infected and someone was forcing her to spread the virus around the world. Her daughter commented that she watched her talk alone and even crying at night. During that time, her psychiatry increased the dose of aripiprazole to $20 \mathrm{mg}$ per day.

A few days after that, she entered a supermarket screaming and threatening to cough on people. The patient was admitted to the Inpatient Unit and aripiprazole was increased up to $30 \mathrm{mg}$ but she is verbally aggressive and demanded to be discharged to continue her duty. During the next days, she continued to be very hostile during interviews and expressed her belief that the best thing to do for the world is to spread the virus to restart a better life in a new order. Aripiprazole was discontinued due to lack of efficacy after the first week in the hospital and cariprazine $3 \mathrm{mg}$ was started at bedtime. Quetiapine $50 \mathrm{mg}$ was added to control insomnia. 
On the third day, cariprazine was raised to $6 \mathrm{mg}$ as it was well tolerated and an improvement in their behavior was experienced in the next days. She started to be concerned for her daughter. She was calmer during interviews and recognized the existence of voices that urged her to infect. The voices gradually diminished and the patient accepted the pathological origin of them a few days later.

After a few days of stability with good mood and cooperativeness, agreeing to follow-up, she was discharged.

\section{Discussion}

Schizophrenia is a severe mental health disorder that requires a psychopharmacological medication as a fundamental part of the treatment. Even though the clinical presentation can be diverse, it usually includes the presence of positive, negative and cognitive symptoms in different proportions. Patients hospitalized for an acute exacerbation usually show prominent positive symptoms. The three clinical cases previously discussed had notable positive symptoms, but they also showed negative and cognitive symptoms during or prior to the episode, which has been shown to influence outcome, functioning and quality of life of the patients.

In this respect, cariprazine was effective in controlling positive symptoms (hallucinations, delusions, disruptive behavior, etc) which is a priority in acute Inpatient Units of Psychiatry. Moreover, the chronicity of this disorder requires a long-term vision, which should always contemplate the impact of a treatment on negative and cognitive symptoms as well. Cariprazine, due to its pharmacological profile, has shown to improve these symptoms on numerous clinical trials ${ }^{19-21}$ and its efficacy was also observed in our clinical cases. The efficacy of cariprazine on negative symptoms was specially outstanding in a patient with long-lasting/persistent negative symptoms.

On the other hand, partial D2 agonist like cariprazine, instead of a total antagonism, has shown efficacy in animal models of substance abuse. ${ }^{22}$ Furthermore, the dopamine receptor D3, distributed throughout the limbic system, including nucleus accumbens which is involved in motivation and reward, has been postulated as a promising target for disorders such as schizophrenia and addictions. ${ }^{23-25}$ Cariprazine is an antipsychotic with the highest affinity for D3 receptors and has shown at least similar efficacy that aripiprazole and bifeprunox on decreasing the reinforcing effect of cocaine and preventing consumption relapses. ${ }^{22}$ Thus, cariprazine could be considered as a first treatment option in psychotic disorders with comorbid substance use. ${ }^{26}$ Efficacy of cariprazine on these situations was observed in two of our clinical cases.

Another aspect to be highlighted of cariprazine was the excellent tolerability and absence of interactions in a patient with physical comorbidity and under antiretroviral therapy. Nowadays, tolerability must be considered a priority in the treatment of schizophrenia, not only in the maintenance treatment but in the acute exacerbations as well. Moreover, adherence to treatment could be improved by reducing the possibility of experiencing antipsychotic side-effects and adding a positive subjective perception of the treatment due to a favorable profile on all the subtypes of symptoms of schizophrenia. In these three clinical cases, tolerability was very good and even the most commonly reported side effect for cariprazine in clinical trials, akathisia, was not observed. ${ }^{27}$ Additionally, cariprazine tolerability was very favorable regarding other adverse effects usually associated to other antipsychotics such as weight gain, metabolic disorders or sedation. Our patients did not experience any of these side effects and the acceptability of the treatment was very good, mentioning that the treatment with cariprazine was very helpful in their global improvement.

A limitation of these clinical reports is the short period of observation to verify the efficacy and tolerability of cariprazine in the long term, especially in chronic and complex disorders like the ones presented here.

In conclusion, cariprazine showed efficacy in treating positive symptoms in these three acute exacerbations of schizophrenia. Its efficacy was also crucial on negative and cognitive symptoms that are usually not easy to manage with current treatments. Furthermore, cariprazine showed an excellent tolerability profile which represents an advantage in the treatment of a chronic disorder like schizophrenia.

\section{Consent for Publication}

Written informed consent has been obtained from all patients to publish the case details. Institutional approval was not required for publication.

\section{Funding}

Recordati provided financial support for the writing of the manuscript.

\section{Disclosure}

Dr Montes has received grants from and served as consultant, advisor, or CME speaker for Almirall, Angelini, 
AstraZeneca, Bristol-Myers Squibb, Eli Lilly, Ferrer, GlaxoSmithKline, ISCIII, Janssen-Cilag, Lundbeck, Neuraxpharm, Otsuka, Pfizer, Qualigen, Recordati, SanofiAventis, Servier, and the Spanish Ministry of Science and Innovation (CIBERSAM). Dr Daniel Hernández-Huerta reports personal fees and non-financial support from Janssen, Casen Recordati, Otsuka, Lundbeck, and Angelini, outside the submitted work. The authors report no other conflicts of interest in this work.

\section{References}

1. Berges A. Schizophrenia. In: Ferri FF, editor. Ferri's Clinical Advisor 2021. Elsevier; 2021:1234.e6-1234.e8.

2. Rice DP. The economic impact of schizophrenia. J Clin Psychiatry. 1999;60:4-6.

3. Mangalore R, Knapp M. Cost of schizophrenia in England. Ment Health Policy Econ. 2007;10:23-41.

4. Freudenreich O, Brown HE, Holt DJ, et al. Psychosis and Schizophrenia. In: Stern TA, Fava M, Wilens TE, Rosenbaum JF, editors. Massachusetts General Hospital Comprehensive Clinical Psychiatry, 2nd. NY: Elsevier; 2018:307-323.

5. Andreasen NC, Arndt S, Alliger R, et al. Symptoms of Schizophrenia: methods, meanings, and mechanisms. Arch Gen Psychiatry. 1995;52(5):341-351. doi:10.1001/ archpsyc. 1995.03950170015003

6. Freudenreich O, Goff DC, Henderson D. Antipychotic. In: Stern TA, Fava M, Wilens TE, Rosenbaum JF, editors. Massachusetts General Hospital Comprehensive Clinical Psychiatry. 2nd ed. NY: Elsevier; 2018:475-488.

7. Gilbert P, Harris MJ, McAdams LA. Neuroleptic withdrawal in schizophrenic patients: a review of the literature. Arch Gen Psychiatry. 1995;52(3):173-188. doi:10.1001/ archpsyc.1995.03950150005001

8. Velligan DI, Weiden PJ, Sajatovic M, et al. The expert consensus guideline series: adherence problems in patients with serious and persistent mental illness. J Clin Psychiatry. 2009;70(Suppl 4):1-46. doi:10.4088/JCP.7090su1cj

9. Kahn RS, Fleischhacker WW, Boter H, et al. Effectiveness of antipsychotic drugs in first-episode schizophrenia and schizophreniform disorder: an open randomised clinical trial. Lancet. 2008;371 (9618):1085-1097. doi:10.1016/S0140-6736(08)60486-9

10. Grootens KP, van Veelen NM, Peuskens J, et al. Ziprasidone vs olanzapine in recent-onset schizophrenia and schizoaffective disorder: results of an 8-week double-blind randomized controlled trial. Schizophr Bull. 2011;37(2):352-361. doi:10.1093/schbul/sbp037

11. Briles JJ, Rosenberg DR, Brooks BA, et al. Review of the safety of second-generation antipsychotics: are they really "atypically" safe for youth and adults? Prim Care Companion CNS Disord. 2012;14 (3):PCC.11r01298. doi:10.4088/PCC.11r01298

12. Kelly DL, Mcmahon RP, Liu F, et al. Cardiovascular disease mortality in patients with chronic schizophrenia treated with clozapine: a retrospective cohort study. J Clin Psychiatry. 2010;71 (03):304-311. doi:10.4088/JCP.08m04718yel

13. Bucci P, Galderisi S. Categorizing and assessing negative symptoms. Current Opin Psychiatry. 2017;30(3):201-208. doi:10.1097/ YCO.0000000000000322
14. De Deurwaerdere P. Cariprazine: new dopamine biased agonist for neuropsychiatric disorders. Drugs Today (Barc). 2016;52(2):97-110. doi:10.1358/dot.2016.52.2.2461868

15. Wesołowska A, Partyka A, Jastrzebska-Wiesek M, et al. The preclinical discovery and development of cariprazine for the treatment of schizophrenia. Expert Opin Drug Discov. 2018;13(8):779-790. doi:10.1080/17460441.2018.1471057

16. European Medicines Agency Reagila Assessment Report. 2017. Available from: https://www.ema.europa.eu/en/documents/assess ment-report/reagila-epar-public-assessment-report_en.pdf.

17. Kiss B, Horváth A, Némethy Z, et al. Cariprazine (RGH-188), a dopamine $\mathrm{D}(3)$ receptor-preferring, $\mathrm{D}(3) / \mathrm{D}(2)$ dopamine receptor antagonist-partial agonist antipsychotic candidate: in vitro and neurochemical profile. J Pharmacol Exp Ther. 2010;333(1):328-340. doi:10.1124/jpet.109.160432

18. Campbell RH, Diduch M, Gardner KN, et al. Review of cariprazine in management of psychiatric illness. Ment Health Clin. 2017;7 (5):221-229. doi:10.9740/mhc.2017.09.221

19. Németh G, Laszlovszky I, Czobor P, et al. Cariprazine versus risperidone monotherapy for treatment of predominant negative symptoms in patients with schizophrenia: a randomised, double-blind, controlled trial. Lancet. 2017;389(10074):1103-1113. doi:10.1016/ S0140-6736(17)30060-0

20. Fleischhacker W, Galderisi S, Laszlovszky I, et al. The efficacy of cariprazine in negative symptoms of schizophrenia: post hoc analyses of PANSS individual items and PANSS-derived factors. Eur Psychiatry. 2019;58:1-9. doi:10.1016/j.eurpsy.2019.01.015

21. Corponi F, Serretti A, Montgomery S, et al. Cariprazine specificity profile in the treatment of acute schizophrenia: a meta-analysis and meta-regression of randomized-controlled trials. Int Clin Psychopharmacol. 2017;32(6):309-318. doi:10.1097/ YIC.0000000000000189

22. Roman V, Gyertyan I, Saghy K, et al. Cariprazine (RGH-188), a D 3-preferring dopamine D 3/D 2 receptor partial agonist antipsychotic candidate demonstrates anti-abuse potential in rats. Psychopharmacology. 2013;226(2):285-293. doi:10.1007/s00213012-2906-7

23. Drago F. The dopamine D3 receptor: from preclinical studies to the treatment of psychiatric disorders. Eur Neuropsychopharmacol. 2015;25(9):1399-1400. doi:10.1016/j.euroneuro.2015.07.025

24. Pich EM, Collo G. Pharmacological targeting of dopamine D3 receptors: possible clinical applications of selective drugs. Eur Neuropsychopharmacol. 2015;25(9):1437-1447. doi:10.1016/j. euroneuro.2015.07.012

25. Michino M, Boateng CA, Donthamsetti $\mathrm{P}$, et al. Toward understanding the structural basis of partial agonism at the dopamine $\mathrm{D}_{3}$ receptor. J Med Chem. 2017;60(2):580-593. doi:10.1021/acs. jmedchem.6b01148

26. Hernandez-Huerta D, Morillo-Gonzalez J. Dopamine D 3 partial agonists in the treatment of psychosis and substance use disorder comorbidity: a pharmacological alternative to consider? CNS Spectr. 2020;29:1-2. doi:10.1017/S1092852920001510

27. Earley W, Durgam S, Lu K, et al. Safety and tolerability of cariprazine in patients with acute exacerbation of schizophrenia: a pooled analysis of four Phase II/III randomized, double-blind, placebo-controlled studies. Int Clin Psychopharmacol. 2017;32 (6):319-328. doi:10.1097/YIC.0000000000000187 


\section{Publish your work in this journal}

Neuropsychiatric Disease and Treatment is an international, peerreviewed journal of clinical therapeutics and pharmacology focusing on concise rapid reporting of clinical or pre-clinical studies on a range of neuropsychiatric and neurological disorders. This journal is indexed on PubMed Central, the 'PsycINFO' database and CAS, and is the official journal of The International Neuropsychiatric Association (INA). The manuscript management system is completely online and includes a very quick and fair peer-review system, which is all easy to use. Visit http://www.dovepress.com/testimonials.php to read real quotes from published authors.

Submit your manuscript here: https://www.dovepress.com/neuropsychiatric-disease-and-treatment-journal 